\title{
The effects of tailored and threatening nutrition information on message attention : evidence from an event-related potential study
}

Citation for published version (APA):

Kessels, L. T. E., Ruiter, R. A. C., Brug, J., \& Jansma, B. M. (2011). The effects of tailored and threatening nutrition information on message attention : evidence from an event-related potential study. Appetite, 56(1), 32-38. https://doi.org/10.1016/j.appet.2010.11.139

Document status and date:

Published: 01/02/2011

DOI:

10.1016/j.appet.2010.11.139

Document Version:

Publisher's PDF, also known as Version of record

Please check the document version of this publication:

- A submitted manuscript is the version of the article upon submission and before peer-review. There can be important differences between the submitted version and the official published version of record.

People interested in the research are advised to contact the author for the final version of the publication, or visit the DOI to the publisher's website.

- The final author version and the galley proof are versions of the publication after peer review.

- The final published version features the final layout of the paper including the volume, issue and page numbers.

Link to publication

\footnotetext{
General rights rights.

- You may freely distribute the URL identifying the publication in the public portal. please follow below link for the End User Agreement:

www.umlib.nl/taverne-license

Take down policy

If you believe that this document breaches copyright please contact us at:

repository@maastrichtuniversity.nl

providing details and we will investigate your claim.
}

Copyright and moral rights for the publications made accessible in the public portal are retained by the authors and/or other copyright owners and it is a condition of accessing publications that users recognise and abide by the legal requirements associated with these

- Users may download and print one copy of any publication from the public portal for the purpose of private study or research.

- You may not further distribute the material or use it for any profit-making activity or commercial gain

If the publication is distributed under the terms of Article $25 \mathrm{fa}$ of the Dutch Copyright Act, indicated by the "Taverne" license above, 


\section{Maastricht University}

The effects of tailored and threatening nutrition information on message attention. Evidence from an event-related potential study

Loes T.E. Kessels ${ }^{1}$, Robert A.C. Ruiter ${ }^{1}$, Johannes Brug ${ }^{2}$ \& Bernadette M. Jansma ${ }^{3}$

1 Department of Work and Social Psychology, Maastricht University, PO Box 616, Maastricht, The Netherlands

2 EMGO Institute, VU University Medical Centre, 1081 BT, Amsterdam, The Netherlands

3 Department of Cognitive Neuroscience, Maastricht University, PO Box 616, Maastricht, The Netherlands

Published as:

Kessels, L.T.E., Ruiter, R.A.C., Brug, J., Jansma, B.M., 2011.

The effects of tailored and threatening nutrition information on message attention. Evidence from an event-related potential study. Appetite, 56, 32-38. doi:10.1016/j.appet.2010.11.139. 


\title{
The Effects of Tailored and Threatening Nutrition Information on Message Attention: Evidence from an Event-Related Potential Study
}

\author{
Loes T.E. Kessels ${ }^{1}$, Robert A.C. Ruiter ${ }^{1}$, Johannes Brug ${ }^{2}$ \& Bernadette M. Jansma ${ }^{3}$ \\ ${ }^{1}$ Department of Work and Social Psychology, Maastricht University, PO Box 616, Maastricht, The Netherlands \\ ${ }^{2}$ EMGO Institute, VU University Medical Centre, 1081 BT, Amsterdam, The Netherlands \\ ${ }^{3}$ Department of Cognitive Neuroscience, Maastricht University, PO Box 616, Maastricht, The Netherlands
}

Recent evidence indicates that attention is higher for individually tailored as compared to nontailored health communications. The present study examined whether the predicted increased attention for the tailored as opposed to general nutrition education messages is moderated by presenting high vs. low threat information about the negative consequences of an unhealthy diet. In a mixed subject experimental design, undergraduate students $(N=34)$ were reading tailored and nontailored nutrition education messages with either high or low threat information about the negative consequences of an unhealthy diet. At the same time, they had to pay attention to specific odd auditory stimuli in a sequence of frequent auditory stimuli (oddball paradigm). The amount of attention allocation was measured by recording event-related potentials (ERPs; i.e., N100, MMN, P300) and reaction times. Result revealed main effects of tailoring and threat, indicating that more attention resources were allocated to tailored vs. non-tailored messages and to low threat vs. high threat messages. The findings confirm that tailoring is an effective means to draw attention to health messages, whereas threat information seems to result in a loss in message attention.

\section{Introduction}

A prerequisite for effective health education is that people have attention for the persuasive message they are exposed to (Blumberg, 2000; McGuire, 1985). The strategy of message tailoring that is, drafting a message that closely responds to the needs of the targeted individual based on an earlier individual assessment is often used by health educators to increase personal relevance of the health information and thus motivate people into more attentive processing of the persuasive information about recommended health behaviors. Indeed, systematic literature reviews suggest that tailoring is associated with stronger behavior change effects than generic health education, especially in nutrition education interventions (Brug, Oenema, \& Campbell, 2003; Kroeze, Werkman, \& Brug, 2006; Noar, Benac, \& Harris, 2007), whereas a recent randomized controlled study confirmed that individually tailored nutrition education messages receive more attention from the reader than non-tailored health communications (Ruiter, Kessels, Jansma, \& Brug, 2006).

Besides message tailoring, a fear appeal (Leventhal, 1971) is often thought as being an effective means to heighten attention for the health information. Several studies have hypothesized that threat perception and fear arousal heighten the relevance of threat-relevant information and, therefore, result in more attentive (systematic) processing of threat-relevant persuasive information (Baron, Logan, Lilly, Inman, \& Brennan, 1994; Gleicher \& Petty, 1992; Ruiter, Kok, Verplanken, \& 
Brug, 2001; see also Ruiter, Abraham, \& Kok, 2001). The findings concerning the effects of threatening information on the systematic processing of health information are, however, not conclusive. Studies that presented threatening health information to those for whom the health threat was high as opposed to low personally relevant suggest an opposite effect of threatening health information on message attention (Freeman, Hennessy, \& Marzullo, 2001; Harris \& Napper, 2005; Keller, 1999; Keller \& Block, 1999; Liberman \& Chaiken, 1992; Sherman, Nelson, \& Steele, 2000; Taubman-Ben-Ari, Florian, \& Mikulincer, 2000). For example, Liberman and Chaiken (1992) presented coffee-drinking and non coffee-drinking participants with threatening information linking coffee-drinking to the development of fibrocystic disease (a precursor to breast cancer). The findings showed that female coffee-drinkers, for whom the message was highly relevant, were less persuaded of the link between caffeine and fibrocystic disease than female non-coffee drinkers. More importantly, coffee drinkers seemed to have systematically processed the threatening parts of the message in a defensive manner. Compared to non-coffee drinkers, they were less critical of information questioning the link between caffeine and fibrocystic disease and more critical of information supporting the link. Thus, people for whom the health message had high personal relevance seemed to process the threat information more defensively than people who already followed the recommendations (see also Harris, Mayle, Mabbott, \& Napper, 2007; Harris \& Napper, 2005; Noar et al., 2007; Sherman et al., 2000).

Defensive reactions to threatening health information have been theoretically explained with the help of cognitive dissonance theory (Festinger, 1957) and Kunda's (1990) argument for motivated reasoning. When experiencing dissonance because the self-image is threatened individuals are motivated to reduce it by changing one of the implicated cognitive or behavioral elements (e.g., perceived risk), for example through biased processing of compromising information (Liberman \& Chaiken, 1992) or message derogation by refuting message claims (e.g., Brown \& Locker, 2009) and evaluating recommendations as not effective (e.g., Keller, 1999).

Recently, Kessels, Ruiter, and Jansma (2010) provided neural evidence for the defensive processing of self-relevant threatening health information during message processing. Kessels et al. (2010) investigated whether reduced acceptance of self-relevant health risk information is already visible in early attention processes, i.e. attention disengagement processes. In an adapted visual selective attention paradigm combined with measures of event-related potentials (ERPs), they found that both smokers and non-smokers responded more efficiently to a target appearing on the same location as a preceding picture when this picture was a high threatening smoking picture than when this picture was a low threatening smoking picture, thus demonstrating a general attention capture effect of threatening health information. However, they also found that smokers responded more easily to a differently located target when this target was preceded by a high threat smoking picture than by a low threat smoking picture. This effect was not observed in non-smokers. The latter finding provided support for the hypothesis that threatening health information causes more efficient attention disengagement among those for whom the health threat is self-relevant (Kessels et al., 2010).

\section{Study Objective and Hypotheses}

The effect of the combined use of message tailoring and threatening health information on the extent of message attention has not been tested yet and is subject of the present research. At a 
more general level, the present study links applied research questions with basic cognitive neuroscience methods to gain more understanding of the cognitive mechanisms that underlie persuasion (cf. Taylor, 2008). The goal of the present study was to investigate the effect of the combined use of message tailoring and threatening health information on attention allocation processes. Similar to the attention paradigm and stimulus materials used in a previous study, nutrition education messages were presented in an oddball attention paradigm (Ruiter et al., 2006). In order to measure attention allocation processes in message tailoring, participants processed two streams of information during the experiment: auditory and textual information. Participants were instructed to read the textual information combining the tailoring and threat manipulation from a screen, and at the same time they were asked to push a button whenever they heard a rare highfrequency tone (i.e., a target stimulus) and to withhold the response whenever a standard lowfrequency tone (i.e., a non-target stimulus) was presented. Response latencies and event-related brain potentials were recorded to quantify the amount of attention allocation to the auditory task.

Event related potentials (ERPs) are generated from a continuous measure of brain activity by means of an electroencephalogram (EEG) (for an introduction, see Fabiani, Gratton, \& Coles, 2000). ERP components frequently elicited in oddball paradigms are the N100, the MMN and the P300. The early $\mathrm{N} 100$ has a negative amplitude that has a maximum peak around $100 \mathrm{~ms}$ after stimulus onset and is usually interpreted as reflecting the distribution of perceptual resources to task-relevant stimulus processing (Coull, 1998; Hillyard, Mangun, Woldorff, \& Luck, 1995; Näätänen, 1992). The N100 shows larger amplitudes whenever the target stimulus is attended to, compared to when there is less or no attention to the target. The Mismatch Negativity (MMN) has a negative peak with a latency of $100-$ 200 ms after stimulus onset has been proposed to reflect comparison of incoming stimuli to a shortlived sensory memory trace of preceding stimuli. The MMN is assumed to be a neural correlate of automatic and pre-attentive change detection, showing larger amplitudes to the extent that the stimuli (targets versus non-targets) are more discriminable (Fabiani et al., 2000; Garrido, Kilner, Stephan, \& Friston, 2009). The P300 has a maximum positive peak around 300 ms after stimulus onset and is functionally related to later conscious, decisional and premotor response related stages (Bentin, Mouchetant-Rostaing, Giard, Echallier, \& Pernier, 1999). The P300 component shows larger amplitudes whenever the target stimulus is attended to and as such provides an index for more controlled attention processes (Coull, 1998; Näätänen, 1992).

Based on previous findings that suggest that people attend more to personally relevant information (Ruiter et al., 2006), we expected that tailored nutrition messages attract more attention than nontailored messages. This in turn - as predicted by resource allocation theory (Kok, 1997; Sanders, 1997) - leads to fewer resources left for carrying out the auditory task. We therefore hypothesized that because of limited resources there should be less auditory attention paid to the target tones during the reading of the tailored nutrition message than during the reading of the non-tailored nutrition message. As a result, we predicted that the mean amplitudes of the N100, MMN and P300 effects would be lower and the reaction times in response to the auditory targets would be slower for the tailored than for the non-tailored intervention group. In addition, Kessels et al (2010) found automatic attention capture effects of threatening health information under conditions of both high and low personal relevance of health information, but also more controlled attention disengagement processes in response to high as opposed to low threatening information only among those for whom the health information was personally relevant. These findings thus suggest that, although 
high threat information automatically attracts more attention than low threat information in early processing stages, in later stages threatening information negatively affects the beneficial effects of message tailoring on attention allocation processes. We therefore expect a main effect of threatening health information on message attention in early stages of attention allocation, reflected in lower mean amplitude scores on the N100 and MMN ERP components in response to the auditory targets in the high vs. low threat condition. In addition, as a result of more defensive responses to personal relevant threatening information in later processing stages an interaction effect between tailoring and threat is expected on the P300 component. That is, the effect of message tailoring on the P300 component in response to the auditory targets will be smaller in the high threat condition than in the low threat condition.

\section{Method}

\section{Participants and Experimental Design}

Forty-one students participated in the experiment. Participants were 19 to 28 years of age (low threat condition: $\mathrm{M}=21.30 ; \mathrm{SD}=2.54$; high threat condition: $\mathrm{M}=22.14 ; \mathrm{SD}=2.57 ; \mathrm{t}(29)=1.06, \mathrm{p}=$ $.30, d=.39)$. All participants were female and reported normal or corrected-to-normal vision and had no medical history of hearing problems. They received course credits or $€ 15$ gift voucher for their participation. In the first ERP-study that measured attention processes for tailored information, tailoring was manipulated as a between-subjects factor (Ruiter et al., 2006). In the present study participants received both a tailored and a non-tailored nutrition education message about fat, vegetable and fruit intake in a counter-balanced order. Each participant was further randomly exposed to either high threat or low threat information about the consequences of having unhealthy eating habits (i.e. high fat intakes and low fruit and vegetable intakes). This threat information was intermingled with the nutrition information. Although a within-subjects manipulation of threat would be preferable, this was thought to be ineffective because of the explicit nature of the threat manipulation. Where both tailoring messages were highly similar in content (see below) the differences between both threat messages is much more visible because they describe different consequences of having an unhealthy diet. When reading both threat messages, the participants could simply combine the consequences of both messages to have a more complete picture of the health threat.

\section{Procedure, Stimulus Materials, and Tasks}

The experiment consisted of two sessions. In the first session participants filled out validated questionnaires to assess the participants' fat, fruit and vegetable intake and their attitude, selfefficacy and intentions related to changing their nutrition behavior (Brug, Steenhuis, van Assema, \& De Vries, 1996; Van Assema, Brug, Ronda, Steenhuis, \& Oenema, 2002). The answers of the respondents were used to construct an individually tailored nutrition message before the start of the second session approximately 1 week later. The content of the tailored messages was a result of three essential strategies of message creation, namely personalization, feedback and content matching (Hawkins, Kreuter, Resnicow, Fishbein, \& Dijkstra, 2008).

In the second session, participants carried out a dual task. In addition to reading tailored and nontailored nutrition education messages from a computer-screen (with a break of approximately 5 min 
in between), they listened to sequences of high- and low-frequency tones and were asked to push a button whenever they heard the rare high-frequency target tone (Hillyard, Mangun, Woldorff, \& Luck, 1995). The software program ERTSVIPL V 3.32c (Beringer, 1987) was used for stimulus presentation and response time latency measurement. The EEG was recorded during the task.

The second session started with the fitting of an electrode cap on the participant's head, after which the participant was taken to a dimly lit, sound-attenuating, electrically shielded cabin and seated in a comfortable chair approximately $80 \mathrm{~cm}$ from the computer screen that situated the participant at eye level to the screen's center. Participants were instructed to fixate on the nutrition information presented on the screen while performing the auditory oddball task and to avoid eye blinks and other body movements as much as possible during presentation of the nutrition messages and auditory oddball task. They were instructed that the reading task and oddball task were equally important.

Both tailored and non-tailored messages had three sections referring to fat, vegetable and fruit intake, respectively. Each section contained about 200 to 250 words with either high threat or low threat information about the negative consequences of unhealthy eating. The remainder of each section in the tailored and non-tailored messages contained information about how to improve nutrition behavior without any threat-manipulation. The tailored message contained between 1550 and 1650 words and the non-tailored message contained 1500 words.

For example, a person whose fat intake was assessed to be 100 grams of fat/day received in the tailored high threat intervention message the following sentence: "You eat approximately an average of 100 gram of fat per day, whereas 75 gram is sufficient. If you eat too much fat at a young age, this will increase your risk of getting heart- and vascular diseases." For the low-threat group the second part of the sentence was presented as follows: "If you eat too much fat, this is not good for your health at later age." In the non-tailored high-threat intervention message the person received the sentence as follows: "On average people in the Netherlands eat 95 gram fat per day, whereas 75 gram is sufficient. If people eat too much fat, this increases the risks of getting heart- and vascular diseases at young age." The second part of this sentence was made less threatening in the nontailored low-threat condition: "If people eat too much fat, this is not good for their health at later age." Examples of a full version of the health message are available through the first author.

In order to measure valid ERP responses, eye movements were minimized by presenting intervention messages on the computer screen word-by-word. Every word appeared on the screen for $250 \mathrm{~ms}$, followed by a black screen for $750 \mathrm{~ms}$. The words were clearly visible and had a minimum length of 2 letters and a maximum length of 16 letters. In the auditory oddball task, the high-frequency $(1,000$ $\mathrm{Hz}$ ) and low-frequency $(500 \mathrm{~Hz})$ auditory tones were presented. The tones were presented $150 \mathrm{~ms}$ after word onset, and the tone length was $100 \mathrm{~ms}$. The high- and low-frequency tones were presented in random order. The high-frequency tones (target tones) had an occurrence probability of $17 \%$; the low-frequency tones (non-target tones) had an occurrence probability of $83 \%$. On hearing a target tone, participants responded as instructed by pressing the button as fast as possible. On hearing a non-target tone, no overt response was required. A practice round of 50 oddball trials without word presentation preceded the experimental task. 
After finishing the dual task participants answered several self-report questions about the information received. Finally, participants were debriefed, paid and asked not to talk about the objectives and topic of the study with fellow students. The entire second session took about $2.5 \mathrm{hr}$.

\section{Measures}

\section{Self-report}

To measure different dimensions of message evaluation, we used self-report items based on previous research into the effectiveness of message tailoring (cf. Brug et al., 1996; Kreuter, Farell, Olevitch, \& Brennan, 2000). For both the tailored and non-tailored nutrition education messages we measured perceived personal relevance of the message ( $1=$ not at all, $7=$ very much), the appreciation of the message on scales from $1=$ unpleasant, to $7=$ pleasant; $1=$ unattractive, 7 = attractive; 1 = uninteresting, 7 = interesting (tailored: Cronbach's $\alpha=.78$; non-tailored: Cronbach's $\alpha$ $=.85)$, the newness and difficulty of the message $(1=$ not at all, $7=$ very much), and the estimated amount of attention allocated (subjective attention) to the message (i.e., "to what extent have you read the information carefully"; 1 = not at all, 7 = very much). We further used six items to measure the extent to which participants felt scared, worried, concerned, anxious, nervous and threatened while reading the information about the health consequences of bad nutrition behavior on a scale from 1 (not at all) to 7 (very much). The scores on these items were averaged to form highly reliable indices (tailored: Cronbach's $\alpha=.94$; non-tailored: Cronbach's $\alpha=.92$ ) of fear arousal.

\section{Reaction times.}

Button-press responses were measured from high tone onset, with a time-out limit of 850 milliseconds (ms). Errors in which no response was registered within $850 \mathrm{~ms}$ after presentation of the auditory target tone, or in which a response was given in reaction to the non-target tone were left out of the analyses of both the reaction time data and the ERP data.

\section{EEG.}

The EEG was recorded from 30 scalp sites (an extended version of the 10/20 system) with tin electrodes mounted in an electrode cap, with the electrodes referenced online to the left mastoid signal. Recordings obtained from the left mastoid electrode were used off-line to re-reference the scalp recordings to the average of the left and the right mastoids. A bipolar montage with electrodes placed on the right and left external canthus, recorded horizontal eye movements. Vertical eye movements and eye blinks were measured by a bipolar montage of electrodes placed on the upper and lower orbital ridge of the left eye. The electro-oculogram was recorded for later off-line rejection of trials contaminated with eye movements. EEG and electro-oculogram signals were digitized at 250 $\mathrm{Hz}$ and amplified by using a 32-channel NeuroScan SynAmps amplifier with a bandpass of $0.05-30 \mathrm{~Hz}$. All electrode impedances (EEG and electro-oculogram) were kept below $5 \mathrm{k} \Omega$.

ERP effects.

From the continuous EEG signal epochs of $900 \mathrm{~ms}$ were obtained, including a $100 \mathrm{~ms}$ pre-stimulus (tone) baseline. Trials with artifacts, including eye movements, were rejected from further analyses (threshold $+/-75 \mu \mathrm{V}$ ). By averaging the remaining artifact-free epochs per participant per condition, we derived the ERP waveforms separately for target and non-target tones from all experimental conditions. The ERP signal was further examined in terms of deviant-standard difference waveforms 
that we computed by subtracting the ERP signal elicited by the non-target tones from that of target tones (separately for each subject, condition and electrode). The difference waveforms were quantified by peak amplitude measures $(\mu \mathrm{V})$, in the time window derived from visual inspection of the grand average (difference) waves. The window for quantifying ERP effects corresponded to the time windows in which the maximal differences between conditions occurred (See Figure 1). The visual inspection resulted in time windows between 100 and $150 \mathrm{~ms}$ after tone onset for the N100, between 200 and 300 ms for the MMN and between 300 and 500 ms for the P300.
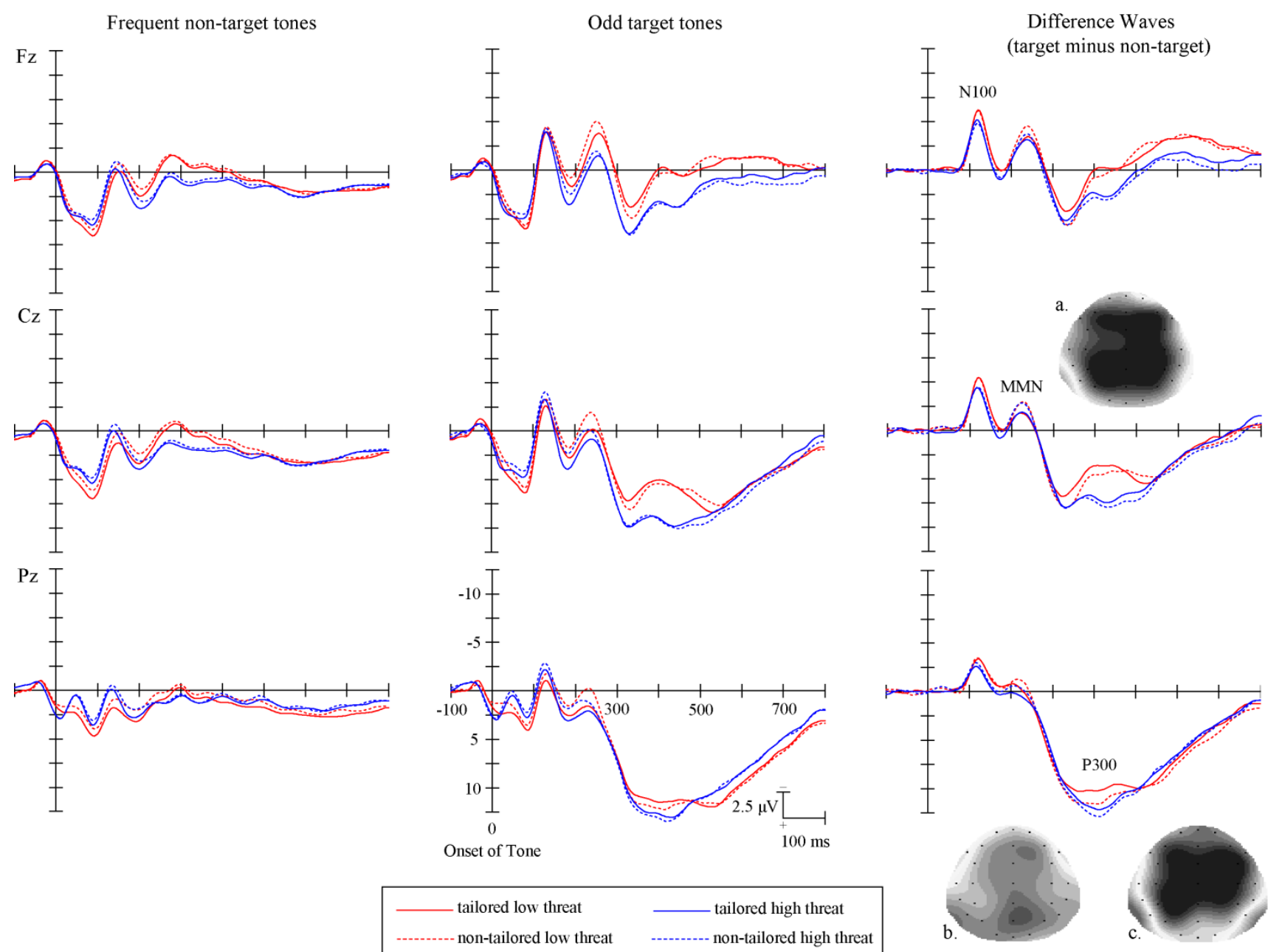

Figure 1: Grand average event-related potentials waveforms for the non-tailored and tailored intervention by level of threat. Data are displayed for all 34 participants for the midline electrodes $F z, C z$, and $P z$. The left column presents the waveforms for the frequent non-target tones. The center column presents the waveforms for the odd target tones. The right column presents the difference waves (target minus non-target tones).The topographical maps were obtained for the MMN (200-300 ms) and the P300 (300-500 ms). The topographical maps present the MMN tailoring effect (part a; non-tailored minus tailored) with a maximum of $1 \mathrm{mV}$ (white) and a minimum of $1 \mathrm{mV}$ (black), the P300 tailoring effect (part b; tailored minus non-tailored)with a maximum of $1 \mathrm{mV}$ (white) and a minimum of 1 $\mathrm{mV}$ (black), and the P300 threat effect (part c; low threat minus high threat) with a maximum of $2 \mathrm{mV}$ (white) and a minimum of $-2 \mathrm{mV}$ (black). 


\section{Analyses}

Mixed model analyses of variance (ANOVA) were used with the within-subjects factor tailoring (tailored vs. non-tailored) and the between-subjects factor threat (high vs. low threat) to compare the four groups on the self-report measures, reaction times and errors.

The ERP analyses were restricted to the midline electrodes because the effects of the N100, MMN and P300 were largest at these sites. The ERP results were subjected to mixed ANOVAs that crossed the within-subjects factors tailoring (tailored vs. non-tailored), electrode sites ( $\mathrm{F} z, \mathrm{Cz}$, and $\mathrm{Pz}$ ) and the between-subjects factor threat (high vs. low threat).

To control for sphericity violations in the analyses of variance, we reported probability values with Greenhouse-Geisser correction for F-tests with more than one degree of freedom in the numerator. The reported estimates of the effect size are the partial eta squared (np2) for the analyses of variance and Cohen's $d$ for the independent-samples t-tests.

\section{Results}

Because the data sets of four participants in the high threat condition and three participants in the low threat condition could not be used because of technical problems or too many mistakes, 34 participants remained in the sample and were included in the analyses with 17 participants in the high threat condition and 17 in the low threat condition.

\section{Premeasures}

Independent-samples t-tests showed that the high and low threat conditions did not differ on the measures of attitude, self-efficacy, intention, and behaviour regarding fat, vegetables, and fruit intake that served as input variables for the nutrition message, ts $<1.93$, ns, ds $<.66$.

\section{Self-report measures}

An overview of the mean scores on the self-report measures can be found in Table 1. Significant main effects of tailoring were found on the measures of perceived personal relevance, $F(1,32)=83.55, p<$ $.001, \eta p 2=.72$, message appreciation, $F(1,32)=34.68, \mathrm{p}<.001, \mathrm{np} 2=.52$, and newness of the information, $F(1,32)=10.22, p<.01, n p 2=.24$. That is, participants perceived the tailored nutrition information as more personally relevant than the non-tailored nutrition information, appreciated the tailored information more, and rated the tailored message as newer. A significant interaction effect of tailoring and threat was found on the perceived difficulty of the nutrition messages, $F(1,33)=5.23$, $\mathrm{p}<.05, \mathrm{np2}=.14$. Independent-samples t-tests showed that the low threat non-tailored message was rated as more difficult to read than the high threat non-tailored message, $t(32)=2.66, p<.05, d$ $=.92$. No effect of threat was found in the tailored messages, $t(32)=-.34, p=.73, d=.12$. In addition, paired-samples t-tests revealed no effects of tailoring in the high and low threat conditions, respectively, ts $<1.73, \mathrm{~ns}, \mathrm{\eta} 2 \mathrm{~s}<.16$.

A significant main effect of threat on the measure of fear arousal indicated that the threat manipulation was successful, $F(1,32)=6.24, p<.05, n p 2=.16$. Participants who read the high threat 
information reported more fear arousal than those that read the low threat information. The main effect of tailoring was also significant, $F(1,32)=4.24, p<.05, n p 2=.12$. The tailored high and low threatening parts were judged as being more fear-arousing than the non-tailored high and low threatening parts.

Finally, no differences were found among the four conditions on participants' reports of the estimated amount of attention that was allocated to the nutrition messages, $\mathrm{Fs}<2.42, \mathrm{~ns}, \mathrm{np} 2 \mathrm{~s}<.07$.

\section{Error Analysis}

False alarms, misses and responses slower than $850 \mathrm{~ms}$ were removed from the ERPs and reaction time data (overall mean $=7.88 \%$; $\mathrm{SD}=3.79 \%$ ) with no differences in the number of removed trials emerging among study conditions, Fs $<1.24$, ns, np2s $<.04)$. Furthermore, trials with EEG artifacts were rejected from the final data set (overall mean $=3.73 \%$; SD $3.12 \%$; no differences among conditions, $\mathrm{F}<.59$, $\mathrm{ns}, \mathrm{np} 2 \mathrm{~s}<.02$ ).

\section{Reaction Times}

Table 1 presents the mean reaction times for detecting the deviant stimuli in the stimulus sequence of auditory tones for all four conditions. In line with our expectations, the mixed ANOVA revealed a significant main effect of tailoring, $F(1,32)=4.38, p<.05, n p 2=.12$. Average reaction times to the target tones were faster for the non-tailored condition than for the tailored condition. Although the reaction times to the target tones seemed to be faster for the high threat condition than for the low threat condition, no significant support for the main effect of threat or the interaction between threat and tailoring was found, Fs $<1.79, \mathrm{~ns}, \mathrm{np} 2 \mathrm{~s}<.05$.

Table 1: Mean reaction times and mean scores on Self-Report Measures of Personal Relevance, Appreciation, Newness, Difficulty, Fear arousal and Attention for the Non-tailored and Tailored Intervention Messages by levels of Threat. SDs are given in brackets.

\begin{tabular}{rrrrr}
\hline & \multicolumn{2}{c}{ Non-tailored } & & \multicolumn{2}{c}{ Tailored } \\
& Low threat & High threat & Low threat & High threat \\
\hline RT & $414.33(42.07)$ & $393.64(39.70)$ & $420.97(41.38)$ & $405.22(43.41)$ \\
Relevance & $2.51(1.33)$ & $2.51(1.12)$ & $5.59(0.98)$ & $4.78(1.70)$ \\
Appreciation & $4.84(1.19)$ & $4.55(1.09)$ & $5.76(0.85)$ & $5.57(0.64)$ \\
Newness & $1.69(0.83)$ & $2.18(0.93)$ & $2.33(1.25)$ & $2.86(1.41)$ \\
Difficulty & $1.71(0.85)$ & $1.12(0.33)$ & $1.41(0.51)$ & $1.35(0.49)$ \\
Fear & $1.88(0.88)$ & $2.58(1.07)$ & $2.12(1.07)$ & $3.05(1.24)$ \\
Attention & $6.12(0.93)$ & $5.82(0.88)$ & $6.35(0.61)$ & $5.88(1.05)$ \\
\hline
\end{tabular}

\section{Peak Amplitude Analyses}

N100.

A significant main effect of electrode sites was found on the mixed ANOVA for the peak amplitudes of the N100 effect, $F(2,64)=65.02, p<.001, \eta p 2=.67$. No significant effects involving the factors tailoring and threat were found, $\mathrm{Fs}<1.55$, ns, $\mathrm{np} 2<.05$, suggesting no differences between study conditions at the midline electrodes on the N100 component (See Table 2). 
$M M N$.

Significant main effects of tailoring, $F(1,32)=13.79, p<.01, \eta p 2=.30$, and electrode sites, $F(1.70$, $54.36)=38.60, \mathrm{p}<.001, \mathrm{np} 2=.55$, were found on the mixed ANOVA for the peak amplitudes of the MMN effect. No significant effect of threat or interaction effects were found, $F_{s}<2.05, n s, n p 2<.06$. In line with visual inspection of the grand average waveforms and the topographical map of the signal distribution, larger peak amplitudes of the MMN effect were found for the non-tailored condition as opposed to the tailored condition at all three midline electrodes (see Table 2).

P300.

The mixed ANOVA on the peak amplitudes of the P300 effect showed significant main effects of tailoring, $\mathrm{F}(1,32)=13.42, \mathrm{p}<.01, \mathrm{np} 2=.30$, threat, $\mathrm{F}(1,32)=11.26, \mathrm{p}<.01, \mathrm{np} 2=.26$, and electrode sites, $F(1.63,52)=50.30, p<.001, n p 2=.61$. No significant interaction effects were found, $F s<3.80$, $\mathrm{ns}, \mathrm{np} 2<.02$. In line with visual inspection of the grand average waveforms of the three midline electrodes, larger peak amplitudes of the P300 effect were found for the non-tailored and high threat conditions than for the tailored and low threat conditions respectively (See Table 2). Although no significant interaction effect involving the factors electrode sites and tailoring was found, visual inspection of the grand average waveforms and the topographical map of the signal distribution indicate a larger P300 tailoring effect at the parietal site than at the frontal and central sites.

Table 2: Mean amplitudes $(\mu \mathrm{V})$ of the $\mathrm{N} 100$ effect $(100-150 \mathrm{~ms})$, the MMN effect (200 - $300 \mathrm{~ms})$ and the P300 effect ( $300-500 \mathrm{~ms}$ ) for the Non-tailored and Tailored Conditions by Level of Threat at midline electrodes. SDs are given in brackets.

\begin{tabular}{|c|c|c|c|c|}
\hline & \multicolumn{2}{|c|}{ Non-tailored } & \multicolumn{2}{|c|}{ Tailored } \\
\hline & Low threat & High threat & Low threat & High threat \\
\hline \multicolumn{5}{|l|}{ N100 } \\
\hline $\mathrm{Fz}$ & $-4.85(2.88)$ & $-4.51(2.81)$ & $-4.61(2.65)$ & $-4.46(3.37)$ \\
\hline $\mathrm{Cz}$ & $-4.13(2.48)$ & $-4.00(2.71)$ & $-3.89(2.39)$ & $-3.65(3.04)$ \\
\hline $\mathrm{Pz}$ & $-2.39(2.00)$ & $-2.61(2.85)$ & $-2.03(2.10)$ & $-2.03(2.83)$ \\
\hline \multicolumn{5}{|l|}{ MMN } \\
\hline $\mathrm{Fz}$ & $-5.53(4.96)$ & $-4.04(3.54)$ & $-3.93(4.56)$ & $-3.37(2.91)$ \\
\hline $\mathrm{Cz}$ & $-3.39(4.60)$ & $-2.89(4.60)$ & $-1.80(4.28)$ & $-1.68(3.67)$ \\
\hline $\mathrm{Pz}$ & $-1.32(3.32)$ & $-0.50(2.92)$ & $-0.19(2.91)$ & $0.81(2.98)$ \\
\hline \multicolumn{5}{|l|}{ P300 } \\
\hline $\mathrm{Fz}$ & $5.59(4.72)$ & $8.26(3.65)$ & $4.62(4.46)$ & $7.52(3.00)$ \\
\hline $\mathrm{Cz}$ & $8.53(4.06)$ & $11.72(3.35)$ & $6.74(3.22)$ & $10.83(4.00)$ \\
\hline $\mathrm{Pz}$ & $11.89(2.35)$ & $14.70(3.71)$ & $10.65(2.07)$ & $13.89(3.96)$ \\
\hline
\end{tabular}

\section{Discussion}

In the present study we examined the effects of combining the methods of tailoring and threat information on attention processes for nutrition information. The P300 ERP results showed that tailored nutrition information as well as low threat nutrition information motivates people into more attentive information processing. Adding to the findings of the first ERP-study on tailoring and message attention (Ruiter et al., 2006), the attention enhancement for the tailored nutrition information was not only shown on the P300 ERP component, but also on the MMN component, 
suggesting an early automatic attention preferences for reading the tailored nutrition information. Furthermore, we were able to replicate the previous ERP-findings by manipulating message tailoring within participants instead of between participants thus reducing between-subjects variation, which might be the reason that we now found a significant effect of tailoring on the reaction times in the expected direction.

The positive attention effects of tailored information were further supported by the self-report measures. Participants perceived the tailored information as more personally relevant than the nontailored information, appreciated the tailored information more, and rated the tailored message as newer. In support of using ERP and reaction time measures in addition to self-report measures, it is further noteworthy that our data did not show a significant difference in subjective estimates of the amount of attention participants paid to the different messages. This study thus provides further evidence for the need to use more direct measures when studying important psychological processes that are conditional to the effectiveness of health communications (Taylor, 2008).

A recent meta-analysis of tailoring studies suggests that presenting tailored messages that focus on threat perceptions leads to less motivation to health behavior change than messages that focus on inducing positive attitudes and higher self-efficacy towards the recommended action (Noar et al., 2007). In line with this finding, Kessels et al. (2010) demonstrated automatic attention capture effects of threatening health information under conditions of both high and low personal relevance of health information, followed by more controlled attention disengagement processes in response to high as opposed to low threatening information only among those for whom the health information was personally relevant. The present study found no support for automatic attention capture for threatening information in early stages of message attention. Despite visible indications of lower mean amplitude scores on the N100 ERP component in response to the auditory targets in the high vs. low threat conditions, the expected main effect of threat in the early processing stage was not supported. Furthermore, the ERP waveforms for the MMN showed no indications of a threat effect. A possible explanation for the missing threat effect on the $\mathrm{N} 100$ and MMN could be the nature of the attention paradigm. While the present study measured divided attention processes for the information, the cueing paradigm used by Kessels et al. (2010) measured direct attention capture processes for the threat information. The indirect nature of the current task might have resulted in reduced sensitivity to measure attention capture processes.

In the later time course stages of message attention, the present study partly supported the expected reduced attention allocation for self-relevant threatening health information. More attention was allocated to low threat compared to high threat information for both tailored and nontailored messages. Despite visible indications of a moderation effect between threat and tailoring information on the P300 ERP component, no empirical support was found for the expected interaction between the threat and tailoring on the amplitude measures of the expected ERP component and on the reaction times. The indirect nature of the experimental paradigm does not exclude the possibility that the enhanced P300 effect in response to the auditory targets during high versus low threatening information was the result of better task performance due to increased levels of threat rather than a defensive response away from threatening health contents. Increased P300 amplitudes to the oddball stimuli under conditions of high anxiety have been reported before, but these findings were limited to responses to novel stimuli in a passive auditory oddball paradigm 
(Grillon and Ameli, 1994). Furthermore, in support of our defensive reaction hypothesis, the enhanced P300 effect in the present study is in line with the findings in the above discussed adapted version of Posner's cueing task that excluded the possibility of interpreting the reported enhanced P300 effects in terms of enhanced performance rather than defensive responding (Kessels et al., 2010).

The self-report results showed that the tailored messages were judged to be more threatening than the non-tailored messages. Tailored messages could create an emotional response such as fear or anxiety (Hawkins, Kreuter, Resnicow, Fishbein, \& Dijkstra, 2008), probably because participants become aware of shortcomings in their nutrition behavior. Participants reported more fear in response to the tailored and the high threat information, but the direct measures showed most attention for the tailored and the low threat information. These findings suggest that different psychological processes explained the effects of both experimental manipulations. Furthermore, the self-report results showed that tailored messages were rated as newer than the non-tailored messages. An explanation could be that participants are more exposed to general nutrition in the media, while they are less familiar with personally tailored messages.

Several methodological issues emerged from the present study that should be followed up in future research. In the present study, threat was presented as a between-subjects factor because we thought that participants would discover the purpose of the threat manipulation when both high and low threat information was presented to the same participant. To overcome the resulting confounding of an experimental manipulation with interpersonal differences in brain structure and activity, future research might opt for a procedure in which the health topic is varied for the high and low threat condition within participants, and the combination of health topic and threat level is then counterbalanced across participants. Still a between-subjects factor is introduced but this variation is less of influence on the research question that is studied. To avoid complex combinations with message tailoring and low statistical power due to lower number of participants in the different cells of the study design, the effect of threat might also be studied for only tailored health education messages given the successful replication of the positive effect of message tailoring on attention processes.

Furthermore, while we measured attention processes for different kind of messages, no other measures of defensive reactions were measured, for example overt self-report measures of defensive avoidance. Such a measure could have given us more insight regarding defensive reactions in the tailored high threat condition compared to other conditions. Third, future studies might counterbalance (preferably within subjects) the assignment of high frequency vs. low frequency tones to target vs. standard auditory tones. When the two tones are counterbalanced, any effects on the difference waves would be entirely due to the oddball effect, thus serving as an index of attention resources, and not due to tone frequency, which probably has nothing to do with attention. Fourth, in future research varying gradations of severity of threat could be tested, in order to determine the optimal level at which attention and processing is greatest.

Overall, the present study showed independent gains in attention for individualized and low threat health information. This gain was empirically shown by a multi-method approach measuring ERPs and reaction times. Attentive processing of provided information is an essential condition for effective health communication. The findings of processing benefits for tailored as opposed to non- 
tailored messages and low threat as opposed to high threat messages suggest that threat is not particularly needed to draw attention to relevant health messages and could actually result in a reduction in attention, but that tailoring seems to be an important means to do so.

\section{References}

Baron, R. S., Logan, H., Lilly, J., Inman, M., \& Brennan, L. (1994). Negative emotion and message processing. Journal of Experimental Social Psychology, 30, 181-201.

Bentin, S., Mouchetant-Rostaing, Y., Giard, M. H., Echallier, J. F., \& Pernier, J. (1999). ERP manifestations of processing printed words at different psycholinguistic levels: Time course and scalp distribution. Journal of Cognitive Neuroscience, 11, 235-260.

Blumberg, S. J. (2000). Guarding against threatening HIV prevention messages: An informationprocessing model. Health Education and Behavior, 27, 780-795.

Brown, S., \& Locker, E. (2009). Defensive responses to an emotive anti-alcohol message. Psychology \& Health, 24, 517-528.

Brug, J., Oenema, A., \& Campbell, M. K. (2003). Past, present, and future of computer-tailored nutrition education. American Journal of Clinical Nutrition, 77, 1028S-1034S.

Brug, J., Steenhuis, I., van Assema, P., \& De Vries, H. (1996). The impact of a computer-tailored nutrition intervention. Preventive Medicine, 25, 236-242.

Coull, J. T. (1998). Neural correlates of attention and arousal: insights from electrophysiology, functional neuroimaging and psychopharmacology. Progress in Neurobiology, 55, 343-361.

Fabiani, M., Gratton, G., \& Coles, M. G. H. (2000). Event-related brain potentials. In J. T. Cacioppo, L. G. Tassinary, \& G. G. Berntson (Eds.), Handbook of psychophysiology (2nd ed., pp. 53-84). New York: Cambridge University Press.

Festinger, L. (1957). A theory of cognitive dissonance. Stanford: Stanford University Press.

Freeman, M. A., Hennessy, E. V., \& Marzullo, D. M. (2001). Defensive evaluation of antismoking messages among college-age smokers: The role of possible selves. Health Psychology, 20, 424-433.

Gleicher, F., \& Petty, R. E. (1992). Expectations of reassurance influence the nature of fearstimulated attitude change. Journal of Experimental Social Psychology, 28, 86-100.

Grillon, C., \& Ameli, R. (1994). P300 assessment of anxiety effects on processing novel stimuli. International Journal of Psychophyiology, 17, 205-217.

Harris, P. R., Mayle, K., Mabbott, L., \& Napper, L. (2007). Self-affirmation reduces smokers' defensiveness to graphic on-pack cigarette warning labels. Health Psychology, 26, 437-446.

Harris, P. R., \& Napper, L. (2005). Self-affirmation and the biased processing of threatening healthrisk information. Personality and Social Psychology Bulletin, 31, 1250-1263.

Hawkins, R. P., Kreuter, M., Resnicow, K., Fishbein, M., \& Dijkstra, A. (2008). Understanding tailoring in communicating about health. Health Education Research, 23, 454-466. 
Hillyard, S. A., Mangun, G. R., Woldorff, M. G., \& Luck, S. J. (1995). Neural systems mediating selective attention. In M. S. Gazzaniga (Ed.), The cognitive neurosciences (pp. 665-681). Cambridge, MA: The MIT Press.

Keller, P. A. (1999). Converting the unconverted: The effect of inclination and opportunity to discount health-related fear appeals. Journal of Applied Psychology, 84, 403-415.

Keller, P. A., \& Block, L. G. (1999). The effect of affect-based dissonance versus cognition- based dissonance on motivated reasoning and health-related persuasion. Journal of Experimental Psychology: Applied, 5, 302-313.

Kessels, L. T. E., Ruiter, R. A. C., \& Jansma, B. M. (2010). Increased attention but more efficient disengagement: Neuroscientific evidence for defensive processing of threatening health information. Health Psychology, 29, 346-354.

Kok, A. (1997). Event-related-potential (ERP) reflections of mental resources: A review and synthesis. Biological Psychology, 45, 19-56.

Kreuter, M. W., Farell, D., Olevitch, L., \& Brennan, L. (2000). Tailoring health messages: Customizing communication with computer technology. Mahwah, NJ: Erlbaum.

Kroeze, W., Werkman, A., \& Brug, J. (2006). A Systematic Review of Randomized Trials on the Effectiveness of Computer-Tailored Education on Physical Activity and Dietary Behaviors. Annals of Behavioral Medicine, 31, 205-223.

Kunda, Z. (1990). The case for motivated reasoning. Psychological Bulletin, 108, 480-498.

Leventhal, $H$ (1971). Fear appeals and persuasion: The differentiation of a motivational construct. American Journal of Public Health, 61, 1208-1224.

Liberman, A., \& Chaiken, S. (1992). Defensive processing of personally relevant health messages. Personality and Social Psychology Bulletin, 18, 669-679.

Marta I. Garrido, M. I., Kilner, J. M., Stephan, K. E., \& Friston, K. J. (2009). The mismatch negativity: A review of underlying mechanisms. Clinical neurophysiology, 120, 453-463.

McGuire, W. J. (1985). Attitude and attitude change. In G. Lindzey \& E. Aronson (Eds.), The handbook of social psychology (pp. 233-346). New York: Random House.

Näätänen, R. (1992). Attention and brain function. Hillsdale, NJ: Lawrence Erlbaum.

Noar, A. M., Benac, C. N., \& Harris, M. S. (2007). Does tailoring matter? Meta-analytic review of tailored print health behavior change interventions. Psychological Bulletin, 133, 673-693.

Ruiter, R. A. C., Abraham, C., \& Kok, G. (2001). Scary warnings and rational precautions: A review of the psychology of fear appeals. Psychology and Health, 16, 613-630.

Ruiter, R. A. C., Kessels, L. T. E., Jansma, B. M., \& Brug, J. (2006). Increased attention for computertailored health communications: An event-related potential study. Health Psychology, 25, 300-306. 
Ruiter, R. A. C., Kok, G., Verplanken, B., \& Brug, J. (2001). Evoked fear and effects of appeals on attitudes to performing breast self-examination: An information-processing perspective. Health Education Research, 16, 307-319.

Sanders, A. F. (1997). A summary of resource theories from a behavioral perspective. Biological Psychology, 45, 5-18.

Sherman, D. A. K., Nelson, L. D., \& Steele, C. M. (2000). Do messages about health risks threaten the self? Increasing the acceptance of threatening health messages via self-affirmation. Personality and Social Psychology Bulletin, 26, 1046-1058.

Taubman - Ben-Ari, O., Florian, V., \& Mikulincer, M. (2000). Does a threat appeal moderate reckless driving? A terror management theory perspective. Accident Analysis and Prevention, 32, 1-10.

Taylor, S. E. (2008). Current issues and new directions in Psychology and Health: Bringing basic and applied research together to address underlying mechanisms. Psychology \& Health, 23, 131-134.

Van Assema, P., Brug, J., Ronda, G., Steenhuis, I., \& Oenema, A. (2002). A short dutch questionnaire to measure fruit and vegetable intake: relative validity among adults and adolescents. Nutrition and Health, 16, 85-106. 